\title{
Contents List
}

Prof. W. V. Vishniac. . . . . . . . . . . . . . . . . . . V

Preface....................... VII

\section{Exobiology}

A. A. Imshenetsky and B. G. Murzakov

Detection of Extraterrestrial Life by Radiometric Techniques . . . . . . . . . .

\section{Radiation Biology}

M. D. Pomerantseva, V. V. Antipov, G. A. Vilkina and B. S. Gugushvili

Chemical Protection against Radiation-induced Genetic Damage during the Period of After-Effects of Gravity Stress . . . . . . . . . . . . . . . . . . .

C. H. YANG and C. A. TobiaS Interaction between Radiation Effects, Gravity and Other Environmental Factors in Tribolium confusum . . . . . . . . . . . . . . . . . . . . . . . . . . . . .

C. H. Bonney, F. N. Beckman and D. M. Hunter

Retinal Change induced in the Primate (Macaca mulatta) by Oxygen Nuclei Radiation

H. BüCKER

The Biostack Experiments I and II aboard Apollo 16 and 17 . . . . . . . . . . .

W. Enge, R. Beaujean, K.-P. Bartholomä and K. Fukui

The Charge Spectrum of Heavy Cosmic Ray Nuclei measured in the Biostack Experiment aboard Apollo 16 using Plastic Detectors . . . . . . . . . . . . . . . . .

R. PFohl, R. Kaiser, J. P. MAssue and P. Cüer

Experimental Methods of Correlation between the Trajectories of Cosmic Heavy Ions and Biological Objects: Dosimetric Results from the Biostack Experiment on Apollo 16 and 17

G. HENIG, E. Schopper, J. U. SCHOtT and W. Rüther

AgCl Detectors in the Biostack II Experiment aboard Apollo 17 . . . . . . . . . .

W. Rüther, E. H. Graul, W. Heinrich, O. C. Allkofer, R. Kaiser and P. Cüer

Preliminary Results on the Action of Cosmic Heavy Ions on the Development of Eggs

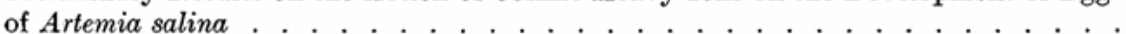

G. Horneck, R. Facius, W. Enge, R. Beaujean and K.-P. Bartholomä

Microbial Studies in the Biostack Experiment of the Apollo 16 Mission: Germination and Outgrowth of Single Bacillus subtilis Spores hit by Cosmic HZE Particles . . . .

H. Planel, J. P. Soleilhavoup, Y. Blanquet and R. KaIser

Study of Cosmic Ray Effects on Artemia salina Eggs during the Apollo 16 and 17 Flights . 


\section{Gravitational Biology}

N. P. Dubinin and E. N. Vaulina

Gravity, Weightlessness and the Genetic Structures of Organisms . . . . . . . . . 93

M. WOJTKOWIAK

Haemodynamic Changes caused in Rats by Prolonged Accelerations . . . . . . . . 103

P. Groza, S. Cananău, E. Daneliuc and A. Bordeianu

Effect of Hypergravity and Hyperthermia on Antidiuretic Hormone Secretion . . . 107

E. V. Moskvitin and E. N. VAuLinA

Effect of Dynamic Factors of Space Flights on the Green Alga Chlorella vulgaris. . . 113

K. V. Smirnov and A. M. UGolev

Digestive and Resorptive Function of the Small Intestine in Stressful Situation . . . 119

L. Novík and J. Mršustová

Respiratory Gas Exchange as an indicator of Changed Radioresistance in Mammals . 125

A. H. Surth, D. F. Raulmann, A. M. Kodama and N. PaCE

Metabolic Responses of Monkeys to increased Gravitational Fields . . . . . . . . . 129

J. R. BELJAN

Osseous Malrepair in Calcium-Deficient States . . . . . . . . . . . . . . . . . 133

H. BJURStedt, G. ROSENhAMER and G. TydÉN

Gravitational Stress and Exercise . . . . . . . . . . . . . . . . . . . . . . . 141

P. Calen, R. Grandpierre and A. Lasnier

Modifications de la perfusion et de la ventilation pulmonaires au cours de l'impesanteur simuléa. . . . . . . . . . . . . . . . . . . . . . . . . . . . 147

N. Pace, D. F. Rahlmann, A. M. Kodama, R. C. Marns and B. W. Grunbaum

A Monkey Metabolism Pod for Space Flight Weightlessness Studies . . . . . . . . 149

YA. A. Vinnikov

The Role of Gravity in the Phylogeny of Structure and Function in Animal Sensors of Spatial Orientation and their predicted action in Weightlessness. . . . . . . . . 159

W. BRIEGLEB

Histological Studies on the Vestibular Organ of Frog Embryos and Larvae after Simu-

lated Weightlessness . . . . . . . . . . . . . . . . . . . 177

T. D. M. ROBERTS

The Stabilizing Effect on the Trunk of Labyrinth and Neck Reflexes acting together on the Limbs . . . . . . . . . . . . . . . . . . . . . . . . . . . . . . . 18

\section{Planetary Quarantine}

L. B. HALL

Ten Years of Development of the Planetary Quarantine Program of the United States 185

V. I. Vashkov, N. V. Ramkova, G. V. Scheglova, L. Z. Skala and A. G. Nekhorosheva

Verification of the Efficacy of Spacecraft Sterilization . . . . . . . . . . . . 199

M. B. Duke and M. A. REYNolds

Lunar Sample Quarantine Procedures: Interaction with Non-Quarantine Experiments 203

H. BüCKer, G. HoRneck, H. Wollenhaupt, M. SchWAGER and G. R. TAYlor

Viability of Bacillus subtilis Spores exposed to Space Environment in the M-191

Experiment System aboard Apollo 16 . . . . . . . . . . . . . . . . . . . . . 209

A. R. Hoffman, W. Stavro, L. W. Mrller and D. M. Taylor

Terrestrial Quarantine Considerations for Unmanned Sample Return Missions . . . . 215

C. C. Gonzalez, W. Jaworski, A. D. McRonald and A. R. Hoffman

Reduction in Microbial Burden of a Spacecraft due to Heating on Entry into the

Atmosphere of Jupiter . . . . . . . . . . . . . . . . . . . . . . . . . 221

A. R. Hoffman, W. Stavro and C. C. Gonzalez

Quarantine Constraints as applied to Satellites . . . . . . . . . . . . . . . . . 229

Index of Authors . . . . . . . . . . . . . . . . . . . . . . . . 235 